\title{
El doctor Eduardo Liceaga, pediatra
}

\author{
Manuel Antonio Baeza-Bacab
}

Universidad Autónoma de Yucatán, Facultad de Medicina, Yucatán, México

\section{Resumen}

Aun cuando se han escrito diversos trabajos acerca de la vida y obra del doctor Eduardo Liceaga, muy poco se menciona acerca de su actividad en el campo de la atención a la salud infantil. Al inicio de su actividad profesional, el doctor Liceaga mostró una inclinación por la atención de los niños enfermos. Preferentemente por los aspectos quirúrgicos, así lo señalan sus primeros trabajos, aunque después también se preocupó por otros temas relacionados con la infancia y, finalmente, por los asuntos sanitarios. El doctor Liceaga fue el médico responsable de la primera sala de niños enfermos que hubo en México en el Hospital de San Andrés, el primer director del Hospital de Infancia, autor de varias publicaciones sobre problemas pediátricos, introductor de la vacuna contra la rabia en México y creador del Hospital General.

PALABRAS CLAVE: Eduardo Liceaga. Pediatría. Hospital General de México.

\begin{abstract}
Although much has been written about Dr. Eduardo Liceaga's life and works, very little is mentioned about his activities in the field of children's healthcare. At the beginning of his professional activities Dr. Liceaga showed an inclination for the care of sick children. His preference for surgical matters is shown by his early works, although later he also took an interest in other childhood-related issues, and ultimately, in healthcare policies. Dr. Liceaga was the physician responsible for the first ward for sick children in Mexico at Hospital de San Andrés, first director of the Hospital de Infancia, and author of several publications on pediatric problems; he introduced the rabies vaccine in Mexico and was the founder of the Hospital General de México
\end{abstract}

KEY WORDS: Eduardo Liceaga. Pediatrics. Hospital General de México.

\section{Introducción}

El doctor Eduardo Liceaga, la figura más prominente de la medicina mexicana y puente entre los doctores Miguel F. Jiménez e Ignacio Chávez, ${ }^{1}$ no solo fue el encargado de la salud pública del país, sino también cultivó la pediatría, fue el médico responsable de la primera sala de niños que hubo en el país en el Hospital de San Andrés, el primer director del Hospital de Infancia, inspirador de tesis inaugurales en la
Escuela Nacional de Medicina y autor de varios trabajos sobre enfermedades de niños y adolescentes.

Aun cuando existen diversos trabajos acerca de la vida y obra del doctor Eduardo Liceaga, poco se ha escrito acerca de su actividad en el campo de la pediatría, por lo que a continuación se presentan algunos aspectos de esta faceta de su vida profesional, que, como escribió el doctor Gregorio Mendizábal en la nota necrológica que publicó la Gaceta Médica de México: "sirva de tributo merecido al ilustre veterano,
Fecha de recepción: 23-01-2017

Fecha de aceptación: 29-08-2017

DOI://dx.doi.org/10.24875/GMM.17003212
Gac Med Mex. 2018;154:398-408

Disponible en PubMed

www.gacetamedicademexico.com 
al campeón esforzado que consagró su vida entera al servicio de la ciencia, de la humanidad y de la patria". ${ }^{2}$

\section{Origen y formación del insigne médico guanajuatense}

Nació el 13 de octubre de 1839 en la ciudad de Guanajuato; sus padres fueron el doctor Francisco Liceaga y doña Trinidad Torres. Inició sus estudios de medicina bajo la dirección de los doctores Ladislao de la Pascua y Gabino Barreda; en todos los años de la carrera obtuvo la mejor calificación, por lo que en 1865 se le entregó la medalla de oro que había instituido el emperador Maximiliano para el alumno que, en cualquier carrera profesional, obtuviera el primer lugar en todos los cursos. ${ }^{3}$

Al fallecimiento de su padre en 1861, el doctor Ignacio Durán, director de la Escuela de Medicina, se convirtió en su protector: le asignó una beca que le permitió continuar sus estudios, lo nombró subprefecto de la Escuela de Medicina y lo incluyó en el seno de su familia y la sociedad; cada vez que obtenía la mejor calificación, le obsequiaba con una comida y todos los domingos por la tarde lo llevaba a la casa del profesor de música Tomás León, donde escuchaban obras clásicas. Fue en esas reuniones donde se formó el gusto del joven estudiante por la música. ${ }^{3}$

Además, el doctor Durán consiguió del emperador Maximiliano la promesa de enviar al joven Liceaga a perfeccionar sus estudios a Europa una vez que hubiese obtenido el título de médico; sin embargo, el 14 de enero de 1866, el mismo día que fue nombrado secretario de la Sociedad Filarmónica Mexicana, se le informó que ya no iba a ser pensionado a Europa, pues el nuevo ministro de Hacienda había reducido la relación de egresos civiles y suprimido la partida correspondiente. ${ }^{4}$

Estos acontecimientos mantuvieron en México al recién graduado, lo que propició que iniciara su actividad profesional en la capital del país. Fue nombrado profesor de física y de historia natural en el Liceo que el emperador acababa de fundar en el antiguo Colegio de San Ildefonso; poco después, al inaugurarse el Conservatorio de Música, fue nombrado profesor de acústica y fonografía. ${ }^{3}$

En el Colegio de San Ildefonso no había libros de texto y las lecciones eran orales. En la cátedra de historia natural se utilizaban plantas vivas o secas y para los animales se tenían figuras o se revisaban ejemplares de los que eran comunes. Sin embargo, la enseñanza de la física exigió un gabinete, pues el que había era antiguo y en tan mal estado que no había un solo aparato completo; fue preciso emprender una tarea de reparación que dio lugar al primer gabinete de física, que daría origen al de la Escuela Nacional Preparatoria. El señor Joaquín Eguía Liz, director del Colegio, quedó tan complacido que le propuso al archiduque Maximiliano que el doctor Liceaga fuera agraciado con la Cruz de la Orden de Guadalupe. En sus memorias señala que aceptó la distinción, pero que nunca la ostentó en su pecho. ${ }^{3}$

\section{El primer "pediatrista" mexicano}

En su libro Historia de la medicina en México. Desde la época de los indios hasta la presente, publicado en 1888, el doctor Francisco Flores escribió que la "pediátrica" es la especialidad que se ocupa de curar las enfermedades de los primeros meses y años de la vida; mencionando que, en México, como en todas partes, es muy antigua, pues los aztecas atendían con sumo cuidado a los niños recién nacidos, pero que no se había llamado la atención sobre la exigencia de estudios especiales para practicarla, sino hasta ese periodo. Aun cuando en el Plan de Estudios del 12 de Noviembre de 1834 se previno oficialmente que se diera en la cátedra de obstetricia la enseñanza de "enfermedades de niños", lo cierto es que nunca se llegó a dar. ${ }^{5}$

Asimismo, el doctor Flores consideraba que era una necesidad de la Escuela de Medicina la creación de ciertas cátedras de clínicas especiales que complementaran la formación profesional, ya que no era raro que los médicos jóvenes no supieran diagnosticar ni recetar a un niño enfermo. Afirmaba que si bien la enseñanza de la pediatría no se había formalizado, se daba importancia a su ejercicio y que desde la creación de la Casa Cuna se observó que las enfermedades de los niños tenían particularidades, pero que fue a partir del establecimiento de una sala de niños en el Hospital de San Andrés y posteriormente del Hospital de Maternidad e Infancia cuando empezaron a formarse "pediatristas", entre quienes destacaba el doctor Eduardo Liceaga (Figura 1). ${ }^{5}$

\section{Médico de niños en el Hospital de San Andrés}

El doctor Luis Fernando Gallardo, concejal de beneficencia del Ayuntamiento de la Ciudad de México, promovió la creación de la primera sala para para la asistencia de niños enfermos en el Hospital de San 


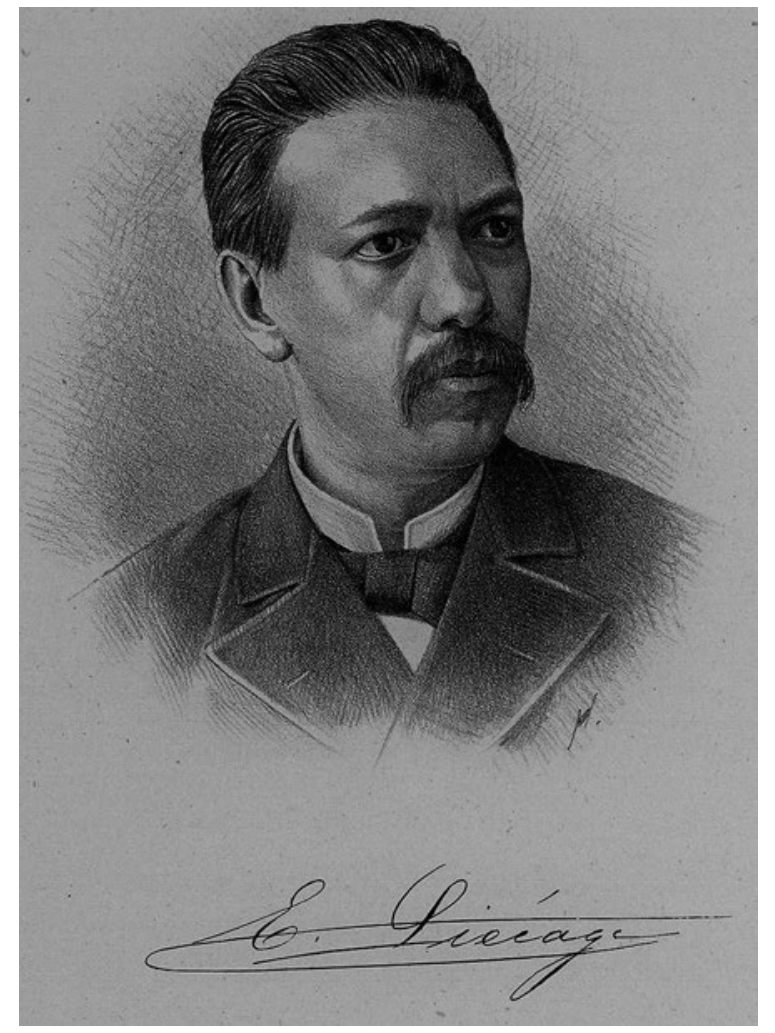

Figura 1. El doctor Eduardo Liceaga, el más antiguo de los "pediatristas" mexicanos. Imagen obtenida de Paz I, editor. Los hombres prominentes de México. México: Imprenta y Litografía de La Patria; 1888.

Andrés, fundada el 7 de febrero de 1868 gracias a la colaboración de sor Juana de Antia, superiora de las Hermanas de la Caridad, que servían en el hospital, y a la buena disposición de los señores Pío Bermejillo y Nicolás de Teresa. ${ }^{4,6}$

El Ayuntamiento abrió un concurso de oposición para proveer la plaza de médico encargado de la nueva sala de niños enfermos. En sus memorias, el doctor Liceaga menciona que cuatro médicos se presentaron a la oposición, uno de ellos acababa de llegar de Europa, donde se había dedicado al estudio de las enfermedades de los niños, otro era un joven médico de Morelia, el doctor Valenzuela, y a los otros dos no los conocía. Relata que el doctor Manuel Carmona y Valle le sugirió la idea de presentarse al concurso, pero que tenía miedo de medir sus fuerzas con los otros concursantes, pues tenía solo dos años de haber egresado de la escuela, por lo que el doctor Carmona le replicó que las derrotas en los concursos no son vergonzosas porque demuestran, al menos, que se tiene ánimo para luchar y que una exposición conveniente proporciona reputación para otro concurso, por lo que se inscribió a la oposición. El doctor Liceaga obtuvo la plaza y, además, se le adjuntó un practicante, el señor Abraham Díaz Gutiérrez; entre ambos conformaron el servicio de la sala. ${ }^{3,5}$

Los exiguos recursos con que dotó el Ayuntamiento a ese departamento no bastaron para cubrir las necesidades del servicio, lo cual fue señalado en diciembre de 1868 en un informe sobre los hospitales, elaborado por el doctor Ramón F. Pacheco, miembro del Consejo Superior de Salubridad y concejal de la Comisión de Hospitales del Ayuntamiento, en el que señaló que la sala era insuficiente y no reunía las condiciones higiénicas necesarias, a tal grado que algunos niños eran internados en petates en el suelo, por lo que se comprometió a encontrar un lugar adecuado. ${ }^{5}$

\section{Médico y director del Hospital de Infancia}

Es necesario señalar que en junio de 1865, el emperador Maximiliano creó una Casa de Maternidad, bajo la protección de la emperatriz Carlota, en el local que ocupaba el Departamento de Partos Ocultos del Hospicio de Pobres, ubicado en la $1^{\text {a }}$. Calle de Revillagigedo. Junto a la Maternidad se construyó la Casa Asilo de San Carlos, que tenía como finalidad dar alimento y educación a los hijos de las mujeres trabajadoras, sin embargo, no llegó a funcionar a causa de la caída del Imperio en $1867.5,6$

Al triunfo de la República, el doctor Ramón F. Pacheco fue nombrado director de la Casa de Maternidad, quien solicitó que se cediera el Asilo de San Carlos a la Casa de Maternidad para poder ampliarla. Una vez que se completó la remodelación consideró que había terreno suficiente para otro edificio y pensó en fundar un hospital de infancia complementario a la Casa de Maternidad. ${ }^{5,6}$

Basado en el informe que rindió a la Comisión de Hospitales del Cabildo, el doctor Pacheco solicitó al Ayuntamiento el traslado de la sala de niños que se encontraba en el Hospital de San Andrés a la parte anexa de la Casa de Maternidad. El 2 de febrero de 1869, el Cabildo aprobó que la sección de niños enfermos pasara a la Casa Asilo de San Carlos, que en lo sucesivo se denominaría Hospital de Maternidad e Infancia. En el acuerdo también se señaló que los practicantes mayores y menores continuaran desempeñando el mismo encargo en el nuevo local. Una semana después se indicó al doctor Eduardo Liceaga, médico de la sección de infancia, que organizara el servicio en tres salas, una destinada a niños, una a niñas y otra a quienes presentaban una enfermedad transmisible. ${ }^{5,6}$ 
En sus memorias, el doctor Liceaga relata que el doctor Pacheco, director del hospital, tuvo la intención de imponerle la obligación de que durmiera en el establecimiento para atender lo que se pudiera ofrecer durante la noche, sin embargo, el doctor Liceaga contestó que él tenía nombramiento de médico de los niños y que no estaba en el servicio por la exigua remuneración que recibía sino para estudiar las enfermedades de la infancia. ${ }^{3}$ En 1870 , la Secretaría de Gobernación separó de la dirección al doctor Pache$\mathrm{co}$, quedando a partir de ese momento el doctor Liceaga como director de todo el establecimiento y el doctor Aniceto Ortega como director de la maternidad. ${ }^{5,6}$

Cuando se organizó el servicio del Hospital de Infancia, el doctor Liceaga comprendió que era insuficiente para una población tan numerosa como la de México y lo amplió, creando una consulta gratuita para niños pobres, cualquiera que fuera su enfermedad. El rápido aumento de la población llevó al doctor Liceaga a solicitar el apoyo de sus amigos los doctores Francisco Chacón, Nicolás San Juan, Ramón Icaza y Manuel Barreiro, así como de los practicantes que habían servido antes: Jesús E. Monjarás, Pedro Noriega, Francisco Hurtado, José Buiza, Lamberto Anaya, Miguel Márquez y Rafael Souza. Pronto fue necesario ampliar la consulta a enfermos de padecimientos quirúrgicos, cualesquiera que fuesen su edad y sexo. ${ }^{3}$ El local fue insuficiente debido a las numerosas cirugías, además de que la sala no recibía luz cenital, por lo que se requería un anfiteatro de operaciones y departamentos anexos. Con el apoyo del diputado general Porfirio Díaz, se logró que el Congreso aprobara la suma de $\$ 10000.00$ para llevarlos a cabo; sin embargo, el dinero no llegó al hospital y el doctor Liceaga tuvo que recurrir de nuevo a sus amigos para realizar la remodelación, que incluyó la adquisición de catres de fierro con rejillas pintados al óleo de color blanco, colchones blandos, ropa de cama nueva y pabellones de muselina blanca. ${ }^{3}$

Para la sala de operaciones se construyó un anfiteatro semicircular monumental con material donado por el general Vicente Riva Palacio; se instaló un tragaluz que permitía la entrada de luz cenital, obsequiado por la señora Catalina Barrón de Escandón. Cuando la obra estuvo terminada fue inaugurada por el señor Carlos Diez Gutiérrez, ministro de Gobernación, quien tuvo la amabilidad de dar el nombre de "Dr. Eduardo Liceaga" al consultorio. ${ }^{3}$

El doctor Liceaga construyó cuatro pequeñas piezas de madera, aisladas, pintadas al óleo para poder ser lavadas siempre que fuese necesario, con los muebles y útiles que se requerían para atender a los niños con enfermedades contagiosas, lo que permitió su aislamiento y evitó la propagación de enfermedades. ${ }^{3}$

Cuando el doctor Roberto Koch anunció al mundo que había descubierto un remedio que podía curar la tuberculosis en el $X$ Congreso Internacional de Medicina, realizado en Berlín en 1890, entre los asistentes se encontraba el doctor Liceaga, quien decidió llevar a cabo una investigación experimental de los efectos de la tuberculina en niños internados en el Hospital de Infancia; como solo contaba con 20 camas, incluyó también algunos enfermos que acudían al consultorio del hospital. Organizó un equipo de trabajo con apoyo de sus compañeros que colaboraban en el consultorio, los practicantes del hospital y algunos profesores de la Escuela de Medicina. ${ }^{3,7}$

De conformidad con lo anterior, se instaló un laboratorio de bacteriología y microscopia en el Hospital de Niños para hacer ahí las diluciones de la linfa y llevarla, de ser necesario, a otros hospitales, de tal modo que estuviera preparada por una sola persona con el conocimiento y las habilidades para esas operaciones; se solicitó al doctor Ángel Gaviño, catedrático de bacteriología, que se hiciera cargo de las diluciones y de realizar personalmente las inoculaciones. El doctor Francisco Hurtado se responsabilizó de los estudios microscópicos de los esputos de los niños con tuberculosis pulmonar, de la pus de las coxalgias y de los análisis de sangre. El doctor Manuel Carmona y Valle, profesor de clínica interna, hizo el diagnóstico de los enfermos de tuberculosis pulmonar y de su observación durante el curso de la aplicación de la tuberculina; el doctor Rafael Lavista, profesor de clínica quirúrgica, diagnosticaba y seguía la evolución de los enfermos de tuberculosis quirúrgica mientras duraba la aplicación del medicamento; el doctor Francisco Chacón se encargó del estudio y vigilancia de los enfermos que recibieron el tratamiento. Los doctores Alfonso Ruiz Erdozáin, Francisco Bernáldez, Aizpuru, Francisco Ortega, Vásquez, Legorreta, Eduardo Vargas, Agustín Chacón, Ramón Icaza, Juan M. Rodríguez, Tobías Núñez, Ricardo Vértiz, Agustín Reyes, Casasola, Ricardo Egea y Vicente Morales se turnaban para vigilar a los enfermos durante el día. Los practicantes tomaban las temperaturas, el pulso y el número de respiraciones de los pacientes cada dos horas durante el día y la noche, anotando todas las modificaciones. ${ }^{3,7}$

Se eligió a un paciente con lupus tuberculoso, tres con ligera infiltración del vértice pulmonar, tres con coxalgia, uno con adenitis cervical, uno con artritis en la rodilla, tres con manifestaciones escrofulosas francas, uno con pleuresía enquistada, uno con mal de 
Pott, uno con padecimiento de los huesos del metatarso y dos con lepra en quienes habían fracasado los tratamientos convencionales. De estos enfermos, 11 eran niños asistidos en el hospital y siete eran de la consulta externa, quienes fueron internados para seguir el tratamiento. En el Hospital de Jesús, el doctor Carmona inoculó a un paciente con escrofulosis y a otro con tuberculoso pulmonar. En el Hospital Concepción Béistegui se inoculó a un enfermo de coxalgia, el profesor Núñez se encargó de una niña con osteítis del húmero derecho y el profesor Lavista de un enfermo de tuberculosis testicular. En total 23 enfermos, 19 niños y cuatro adultos. ${ }^{?}$

Según la recomendación del doctor Koch no se incluyó a los enfermos con tisis pulmonar avanzada ni a enfermos con sospecha de granulaciones cerebrales o meníngeas, lesiones renales, cardiacas o de los vasos sanguíneos gruesos. El estudio se inició el 15 de enero de 1891 con $1 \mathrm{~g}$ de linfa proporcionado por el doctor Alberto Escobar, director del Hospital Militar de Instrucción; al agotarse la tuberculina se continuó con la que el señor presidente de la República consiguió para el estudio y posteriormente con la linfa proporcionada por el señor Peón, de Yucatán, y el señor Ramírez de Arellano, del Consejo de Salubridad. ${ }^{7,8}$

Las observaciones fueron analizadas y comentadas entre los médicos participantes, quienes llegaron a las conclusiones siguientes: los casos de tuberculosis pulmonar incipiente tuvieron una evolución satisfactoria, pero en los casos de tuberculosis pulmonar crónica, más o menos avanzada, los resultados fueron variables, dependiendo de la severidad de las lesiones y la intensidad de los síntomas, como tos, disnea, elevación de la temperatura, abundancia del sudor, pérdida de peso, entre otros. Casi todos los casos de tuberculosis quirúrgica mejoraron favorablemente, así como la niña con lupus, lo cual animó al grupo a seguir empleando la tuberculina en esa enfermedad. La tuberculina fue tan eficaz en los enfermos de lepra, que desde entonces se aplica a los enfermos con lepra con las formas manchada y tuberculosa; no se encontró alivio en las formas graves ni en las que dependen directamente del sistema nervioso. ${ }^{3,7}$

Adicionalmente, el doctor Liceaga describió detalladamente la forma de administrar la tuberculina, para que el resto de los médicos aplicaran el tratamiento en las formas de lepra señaladas; recomendó el aislamiento de los enfermos, el aseo personal frecuente y la limpieza escrupuloso de los vestidos, una alimentación sencilla pero nutritiva y la atención de todas las complicaciones. ${ }^{3,7}$

\section{Las tesis de pediatría en la época del Hospital de Maternidad e Infancia}

En el Hospital de Maternidad e Infancia no solo floreció la atención a los niños enfermos, sino también se desarrolló la atención a los recién nacidos, lo que se acompañó de tesis inaugurales con temas pediátricos y neonatales de los estudiantes de la Escuela Nacional de Medicina. Entre ellas sobresalen la de Mariano Herrera, Algunas consideraciones sobre pediátrica; la de Francisco García Luna, Utilidad de las incubadoras y de su complemento el gavage; la de Federico Martínez, Ligeros apuntes sobre higiene de la primera infancia; la de Alberto Limón, Ventajas que tiene la ligadura tardía del cordón umbilical; y la de Roque Macouzet, El lavado de estómago en los niños, entre otras. En la Tabla 1 se enlistan las tesis con temas pediátricos que se presentaron en la Escuela Nacional de Medicina entre 1869 y 1905, periodo de existencia del Hospital de Maternidad e Infancia. ${ }^{9,10}$

La tesis inaugural de Mariano Herrera, presentada en 1881, merece mención especial ya que constituye un libro de texto; en sus 200 páginas aborda los aspectos básicos de la pediatría. En la introducción, el autor señala que dos motivos lo llevaron a tomar el tema como trabajo inaugural: su relevancia y la falta casi completa de conocimientos que tenían los estudiantes sobre la materia al salir de la escuela profesional. Fue tan importante la tesis, que el doctor Francisco Flores señaló que a finales del siglo XIX en México casi no existían trabajos sobre pediatría, con excepción del estudio de Mariano Herrera, dedicado al "insigne especialista en enfermedades infantiles doctor Eduardo Liceaga"5,11 (Figura 2).

\section{Los niños, los primeros vacunados contra la rabia}

Después de seguir paso a paso durante varias semanas la técnica de las inoculaciones preventivas de la rabia en el Instituto Pasteur de París, el doctor Liceaga regresó a México con el cerebro de un conejo inoculado con rabia. Después de 22 días de travesía llegó a la ciudad de México el 10 de febrero 1888 y de inmediato se puso a trabajar en colaboración con los doctores Nicolás Ramírez de Arellano y Agustín Reyes, y del veterinario José de la Luz Gómez, iniciando las inoculaciones de conejos en el Laboratorio de Bacteriología del Consejo Superior de Salubridad..$^{12,13}$ 
Tabla 1. Tesis sobre temas pediátricos realizadas en la Escuela Nacional de Medicina de 1869 a 1905

\begin{tabular}{|c|c|c|}
\hline Año & Autor & Título \\
\hline 1870 & Víctor Salle & De la sífilis congénita y hereditaria \\
\hline 1871 & Ricardo Juvera & Gangrena de la boca en los niños \\
\hline 1873 & Gregorio Vargas & ¿Existe el empacho en los niños? \\
\hline 1878 & Emilio García & Accidentes de la clorosis en los niños \\
\hline \multirow[t]{2}{*}{1879} & Daniel Muñoz y Lumbier & Breves consideraciones en apoyo de la ligadura tardía del cordón umbilical \\
\hline & Ramón Ruiz & Estudio sobre el tratamiento de los cálculos vesiculares en los niños \\
\hline \multirow[t]{2}{*}{1881} & Lamberto Ayala & Breves consideraciones sobre el tratamiento de la tos ferina \\
\hline & Mariano Herrera y Jayme & Algunas consideraciones sobre pediatría \\
\hline 1882 & Carlos Amezcua & Breves estudios sobre la circuncisión en los recién nacidos como medio profiláctico \\
\hline \multirow[t]{6}{*}{1883} & Miguel Barragán & Ligeros apuntes sobre el infanticidio en México \\
\hline & Francisco de P. Bernáldez & Breves consideraciones sobre la tuberculosis en la infancia \\
\hline & F. A. R. De Poincy & Estudio practico sobre la sífilis infantil hereditaria y adquirida \\
\hline & Ignacio Fernández Ortigoza & Apuntes sobre la alimentación en la primera edad \\
\hline & Francisco Hurtado & $\begin{array}{l}\text { Los cálculos vesicales en los niños, algunas reflexiones acerca de lo que se observa en México sobre esta } \\
\text { afección }\end{array}$ \\
\hline & Agustín Navarro y Cardona & a Apuntes sobre la alimentación en la primera infancia \\
\hline \multirow[t]{2}{*}{1886} & Rafael Sausa y González & Algunas consideraciones sobre estadísticas de enfermedades de niños \\
\hline & Guillermo Senisson & $\begin{array}{l}\text { Breve estudio sobre las causas más frecuentes de retención de orina en el niño y medios más apropiados } \\
\text { para combatirla }\end{array}$ \\
\hline \multirow[t]{2}{*}{1888} & Ramón Estrada & Algunas ligeras consideraciones sobre la falta de higiene infantil en México \\
\hline & Samuel Morales Pereira & Algunas consideraciones sobre las causas que motivan la gran mortalidad de la primera infancia \\
\hline \multirow[t]{4}{*}{1889} & Daniel Herrera & Ligero estudio sobre la alimentación de los niños \\
\hline & Roque Macouzet & El lavado de estómago en los niños \\
\hline & Agustín Quintanar & Ensayo de estadística de mortalidad infantil en México \\
\hline & Daniel M. Vélez & Consideraciones higiénicas relativas a la vista del niño en la escuela \\
\hline 1891 & Carlos Cuesta & Breve estudio sobre la ligadura del cordón umbilical \\
\hline 1892 & Esteban J. Campos & Muerte aparente de los recién nacidos \\
\hline 1894 & Cruz J. Barrera & Examen clínico de los niños \\
\hline \multirow[t]{3}{*}{1895} & Cruz Barreda & Breve estudio sobre la bronconeumonía infantil en México \\
\hline & Alberto Limón & Ventajas que tiene la ligadura tardía del cordón umbilical \\
\hline & Genaro Sandoval & Preceptos generales de higiene escolar \\
\hline \multirow[t]{3}{*}{1896} & Félix Béistegui & Ligeras consideraciones sobre higiene cerebral escolar \\
\hline & Francisco Romero Gámez & Breve estudio sobre las diarreas en los niños \\
\hline & Francisco García Luna & Utilidad de las incubadoras y de su complemento el gavage \\
\hline \multirow[t]{4}{*}{1897} & Manuel Cruz & Breves consideraciones sobre la higiene de la infancia \\
\hline & Jacinto García Sánchez & Algunas consideraciones acerca de la alimentación de los niños \\
\hline & Enrique E. Graue & Oftalmía purulenta de los recién nacidos \\
\hline & Guillermo Ferrer & Breves apuntes sobre higiene alimenticia en los recién nacidos \\
\hline
\end{tabular}


Tabla 1. Tesis sobre temas pediátricos realizadas en la Escuela Nacional de Medicina de 1869 a 1905 (continuado)

\begin{tabular}{|c|c|c|}
\hline Año & Autor & Título \\
\hline \multirow[t]{4}{*}{1898} & Nicolás Guerola & Oftalmía purulenta en los recién nacidos, bacteriología y tratamiento \\
\hline & Manuel Mestre Chigliazza & Breves apuntes sobre la enteritis infantil \\
\hline & Pedro M. Muro & Algunas consideraciones sobre la tos-ferina \\
\hline & Reynaldo Narro & Infección intestinal en el niño \\
\hline \multirow[t]{3}{*}{1899} & Mariano Zertuche & $\begin{array}{l}\text { Lactancia artificial, estudio acompañado de los análisis de diversas leches recogidas en establos, } \\
\text { expendios y hospitales }\end{array}$ \\
\hline & Juan B. Amador & Estudio sobre las diarreas de la infancia y su tratamiento \\
\hline & Federico Martínez & Ligeros apuntes sobre la higiene de la primera infancia \\
\hline \multirow[t]{3}{*}{1900} & Enrique A. Castillo & Diagnóstico diferencial de las meningitis en los niños \\
\hline & Bulmaro Flores & Breves apuntes acerca de las enfermedades escolares y su profilaxia \\
\hline & Nicolás Guerola & Oftalmía purulenta en los recién nacidos, bacteriología y tratamiento \\
\hline \multirow[t]{2}{*}{1901} & Samuel H. Salazar & Breves consideraciones sobre la sífilis hereditaria en México \\
\hline & Miguel M. Silva & Algunas consideraciones sobre bronconeumonía infantil \\
\hline \multirow[t]{2}{*}{1902} & Crisóforo Contreras & Algunas consideraciones sobre la infección intestinal aguda en la primera infancia \\
\hline & Ricardo Villafuerte & La profilaxia de la oftalmía purulenta \\
\hline \multirow[t]{2}{*}{1903} & J. Trinidad Luna & Higiene escolar \\
\hline & Guadalupe Sánchez & Raquitismo \\
\hline \multirow[t]{2}{*}{1904} & Ramón E. Garduño & Tratamiento de las formas clínicas de la diarrea infantil \\
\hline & Jesús Rodríguez Tovar & Enfermedades de los niños que producen mayor cifra de mortalidad en México \\
\hline \multirow[t]{2}{*}{1905} & Lauro Camarillo & Algunas consideraciones acerca de la lactancia artificial \\
\hline & Eduardo Uribe & Breves consideraciones sobre la oftalmología purulenta y su tratamiento \\
\hline
\end{tabular}

Al igual que Pasteur, el primero en recibir la vacuna antirrábica elaborada en México por el doctor Liceaga fue un niño, Isidro Delgadillo, de 12 años, quien fue mordido en la pierna derecha el día 20 de abril de 1888 por un perro que se presumía rabioso. En total tenía cinco mordeduras profundas en la pantorrilla, por lo que se consideró probable que el niño contrajese la rabia. Los padres de Isidro se enteraron por el periódico que el doctor Liceaga, famoso y notable en la capital, había traído desde París la vacuna contra la rabia y llevaba algún tiempo trabajando en ella; el 23 de abril llevaron a su hijo a las instalaciones del Consejo, solicitando que fuera vacunado. ${ }^{12-14} \mathrm{La}$ primera inyección se administró a las 18:50 horas de ese mismo día; el doctor Agustín Reyes introdujo una jeringa con el caldo esterilizado debajo de la piel del hipocondrio derecho del niño. Esta inoculación se hizo sin tener una confianza absoluta en la vacuna, ya que todavía no se tenía completa la seriación de las médulas, pues no se había logrado que todos los días muriera un conejo inoculado de rabia, por lo que se sustituyeron las series faltantes con médulas conservadas en glicerina según una idea del doctor Ramírez de Arellano. El 30 de abril se procedió a una nueva serie y el 10 de mayo se inició la tercera y última; con estas inoculaciones se evitó la muerte del paciente y se logró prevenir la enfermedad. Poco después se administró la vacuna con igual eficacia a los niños Gregorio Flores y Luz García. ${ }^{12-14}$

\section{Las publicaciones pediátricas del doctor Liceaga en Gaceta Médica de México}

En la velada realizada por la Academia Nacional de Medicina para conmemorar el centenario del nacimiento del doctor Eduardo Liceaga, el 13 de octubre de 1939 el doctor Alfonso Pruneda, secretario perpetuo de la Academia Nacional de Medicina, leyó una semblanza del homenajeado, en la que señaló que durante 50 años de vida académica activa publicó 35 trabajos 


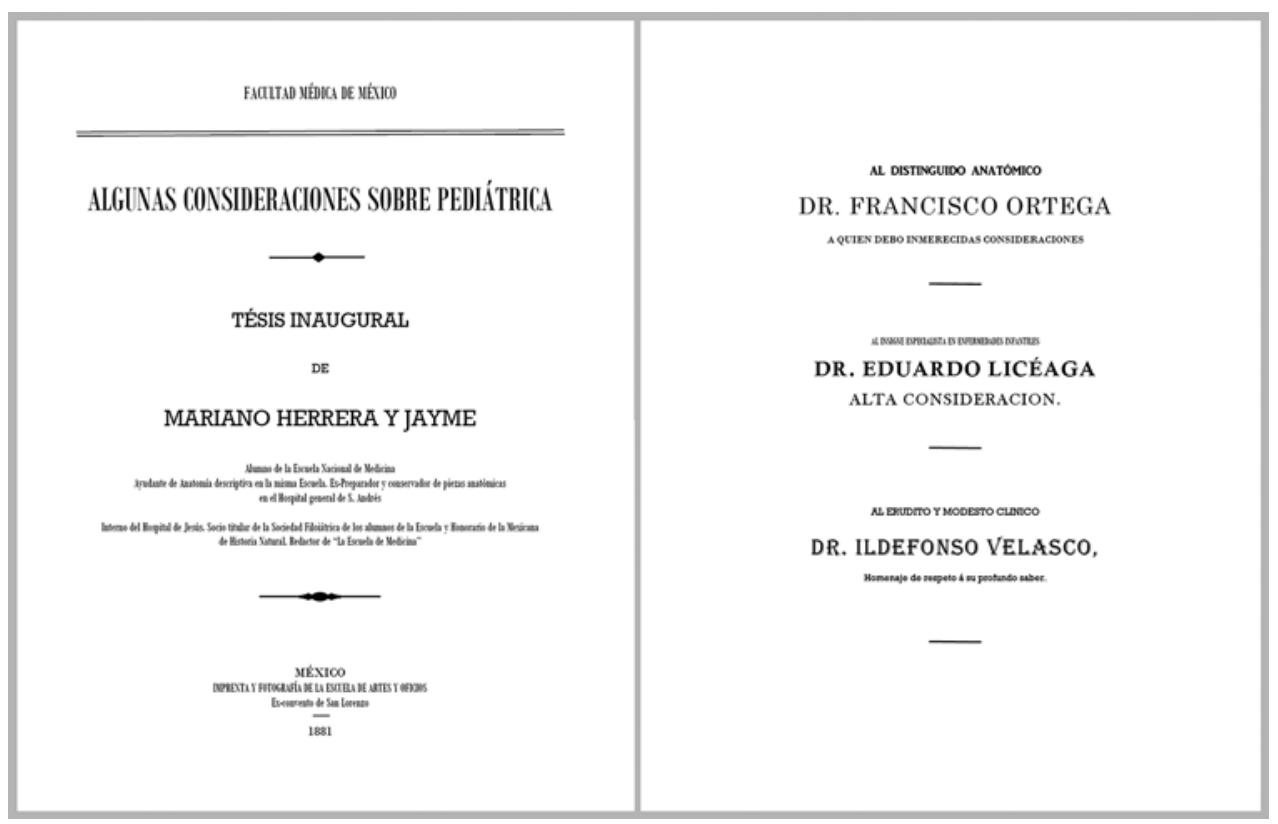

Figura 2. Carátula de la tesis inaugural de Mariano Herrera y Jayme, alumno de la Escuela Nacional de Medicina, 1881.

en Gaceta Médica de México, ${ }^{15}$ de los cuales 13 se refieren a temas pediátricos. El primero, que muy probablemente corresponde a lo que hoy se llama trabajo de ingreso, se tituló "Metritis crónica. Dispepsia. Neurosis sintomáticas", y tiene fecha del 12 de julio de 1868; su último trabajo lo publicó cuando tenía 75 años y se denominó "Importancia de divulgar la higiene personal", fechado el 16 de diciembre de 1914.16,17

Los trabajos del doctor Liceaga confirman su interés y compromiso con la salud infantil y hace recordar su frase: "yo no estoy en el servicio de niños por la exigua remuneración que recibo sino para estudiar las enfermedades de la infancia". ${ }^{3}$ Casi todas sus observaciones las realizó en pacientes que acudían a consulta o estaban internados en el Hospital de Infancia, donde recibían tratamiento médico o quirúrgico. Su primera participación con un tema pediátrico en la Academia fue fortuita: la noche del 9 de marzo de 1870, el doctor Lauro Jiménez tenía concedido el uso de la palabra desde la sesión anterior, pero se reservó sus reflexiones acerca de la afección cerebral que padecía un aeronauta que había caído de un globo en la plaza de toros, a la espera de la llegada de los doctores Carmona y Reyes, con quienes discutía el diagnóstico. Esto permitió al doctor Liceaga hablar acerca de una niña de cuatro a cinco años afectada de croup (laringotraqueobronquitis), a quien curó con jarabe de ipeca que le ocasionó vómitos frecuentes. ${ }^{18}$

Los artículos posteriores abordan temas quirúrgicos. El primero corresponde a una operación de traqueotomía recopilada por Juan Cabral, un alumno de la
Escuela de Medicina. Se trató de un niño de 10 meses de edad que sufría dificultad respiratoria y tos de dos meses de duración, en esas circunstancias la madre se enteró que el doctor Liceaga, especialista en enfermedades de niños, daba consulta gratuita todos los días en el Hospital de Maternidad e Infancia, por lo que llevó a su hijo. Después de examinarlo, el doctor Liceaga formuló el diagnóstico de compresión de la tráquea por dos tumores ganglionares. Por indicios de asfixia inminente, los doctores Liceaga, Ortega y Casa-sola determinaron realizar una traqueotomía, para lo cual se colocó al niño en una mesa frente a una ventana y el doctor Liceaga procedió con esmero y habilidad a realizar la operación, que tuvo una duración de 10 minutos. Sin embargo, a causa de la asfixia previa, fue necesario reactivar la sensibilidad del niño con electricidad dinámica en los músculos y la piel. A los cinco días desaparecieron los tumores con la aplicación de ungüento mercurial y ioduro de potasio; la cánula fue retirada un mes después. Es importante señalar tres reflexiones del doctor Liceaga:

1. La electricidad es de gran utilidad en los casos de asfixia y quedó establecido su empleo en el hospital para todos los niños con ese estado.

2. La traqueotomía no es tan grave y se debe practicar en las enfermedades que pueden causar la muerte.

3. No es necesario retirar la cánula poco a poco. ${ }^{19}$ Los otros trabajos quirúrgicos se refieren, por lo general, al tratamiento de infecciones de huesos y articulaciones, probablemente porque en ese tiempo 
su prevalencia era elevada. Entre sus reportes se encuentra una resección subperióstica de la extremidad superior del fémur con regeneración del hueso en una niña de cuatro años; las conclusiones del trabajo señalan que la operación logró la regeneración del hueso y la restauración de la articulación, la cual no se perdió gracias a que la resección se realizó por el método sub-perióstico. ${ }^{20}$ Otro caso se refiere a una niña de siete años, internada en el Hospital de Niños por artritis supurada en ambos codos, hombro izquierdo y articulación tibiotarsiana, así como periostitis de tibia derecha consecutivas a viruela. En ese caso, el doctor Liceaga llamó la atención acerca de lo siguiente:

1. La elevada frecuencia de la artritis secundaria a la viruela.

2. Que el tratamiento de la periostitis con incisiones, curación con alcohol y empaque algodonado evita la difusión de la inflamación.

3. Que la artritis grave puede ser manejada con inmovilización de la articulación, tratamiento antiescrofuloso y buena higiene. ${ }^{21}$

En la sesión de la Academia del 15 de mayo de 1878, el doctor Liceaga presentó el caso de un niño de 14 años operado dos años antes en el Hospital de Infancia por una periostitis difusa supurada de la tibia derecha. La historia clínica del paciente había sido recopilada por el practicante José G. Buiza y en ella se mencionaba que se realizó resección de la tibia en la mayor parte de su diáfisis, señalando que la regeneración era completa, que el hueso estaba más voluminoso, la cicatriz era sólida y se podían ejecutar los movimientos, por lo que se consideró que el enfermo estaba totalmente curado. ${ }^{22,23}$

Otro caso que presentó fue el de un paciente de 17 años, con mal vertebral de Pott, osteítis central de los cuerpos vertebrales dorsales y absceso de gran tamaño por congestión, quien fue tratado quirúrgicamente con lavados de alcohol fénico y colocación en un aparato de Bonnet. ${ }^{24}$

El doctor Liceaga también publicó casos de cálculos vesicales operados con buen éxito en el Hospital de Niños. El primero de ellos fue un niño de siete años, operado en colaboración con los doctores Muñoz y Martínez del Rio; al paciente se le retiró un cálculo irregular de color gris que pesaba 30 gramos y medía $37 \times 33 \mathrm{~mm}$. La segunda historia correspondió a un niño de cinco años, a quien se le extrajo un cálculo elíptico de $16 \times 13 \mathrm{~mm}$, rugoso, friable, parecido a una fresa pero de color amarillo sucio. ${ }^{25} \mathrm{El}$ último caso fue presentado en la sesión de la
Academia del 8 de junio de 1881; se trató de un niño de nueve años con un cálculo en la vejiga, que fue extraído sin complicaciones; el cálculo, de color rojizo, estaba formado por ácido úrico y uratos. ${ }^{26}$

Los trabajos restantes se refieren a temas médicos, por ejemplo, una parálisis espinal pseudohipertrófica en un niño de nueve años (atendido inicialmente por el doctor Vicente Morales, encargado del Segundo Departamento del Hospital de Infancia), quien mejoró física y mentalmente gracias a la educación que se le dio en el hospital y al tratamiento: hidroterapia, buena alimentación, faradización muscular y estricnina. ${ }^{27}$

El doctor Liceaga también describió una anomalía congénita; un niño de tres meses de edad con el pabellón auricular derecho adherido solo a nivel del lóbulo. Después de una amplia revisión de la literatura médica, el doctor Liceaga concluyó que la deformidad no había sido descrita hasta ese momento. ${ }^{28}$

Uno de sus trabajos, aunque incluido en la sección de Terapéutica Quirúrgica de la Gaceta, en realidad fue un caso de escoliosis dorsal derecha manejada con tratamiento médico. Se trató de una joven de 16 años de edad, muy alta, delgada y pálida, con desviación lateral de la columna vertebral, a quien se mantuvo por espacio de 11 meses en forma continua en un canal de Bonnet, posteriormente se le permitió levantarse y se le mantuvo erguida por medio de un corsé de fieltro perforado, confeccionado mediante un molde de yeso con la misma técnica empleada por Sayre en Nueva York. Los beneficios del tratamiento fueron notorios, por lo que el doctor Liceaga concluyó que para el tratamiento no se requerían procedimientos violentos ni operaciones quirúrgicas, si bien no lo había comparado con el método de Calot y no se había cerciorado si conllevaba un verdadero progreso científico. ${ }^{29}$

El último trabajo del doctor Liceaga es el comentario sobre un libro publicado en 1910 por los profesores John W. Ritchie y Joseph S. Caldwell con el nombre de Primer of Hygiene; Being a Simple Textbook on Personal Health and How to Keep it, el cual fue traducido, adaptado y ampliado por el doctor Manuel Uribe y Troncoso en 1913 con el nombre de Cartilla de higiene personal. El doctor Liceaga menciona que si bien la obra estaba dirigida a los niños escolares, también parecía destinado a servir de guía a maestros y madres, quienes debían inculcar a los niños las primeras enseñanzas de la higiene personal. Termina su trabajo pidiendo a la Academia que conceda su atención a la utilidad de hacer propaganda a la higiene individual como base de la higiene pública. ${ }^{17}$ 
La revisión de las publicaciones permite observar que no todos los trabajos están firmados por el doctor Liceaga, ya que con frecuencia se apoyaba en sus practicantes, como los señores Buiza o Cabral, para la elaboración de la historia clínica del paciente y la descripción de las acciones terapéuticas y la evolución de los pacientes, las cuales se presentaban de forma oral en las sesiones semanales de la Academia y posteriormente se publicaban en la Gaceta, proceder que apoyaba la formación profesional de sus practicantes, tal como sucede en la actualidad con los médicos residentes.

\section{La opera magna: el Hospital General}

Desde 1881, la comunidad médica había hecho notar a las autoridades del país, la conveniencia de edificar un hospital general adecuado a las necesidades de la ciudad. Pasaron muchos años para que esta idea se hiciera realidad. En el informe presidencial de 1888 se mencionó que la Lotería de la Beneficencia Pública entregaría al gobierno $\$ 600000.00$ pesos para la construcción de un hospital; en el informe de 1890, el presidente Porfirio Díaz comentó que estaban concluidos los planos del Hospital General y que se comenzaría su construcción. Fue hasta noviembre de 1895 cuando el ministro de Gobernación, el general Manuel González Cosío, comisionó al doctor Eduardo Liceaga y al ingeniero Roberto Gayol Soto, para desarrollar el proyecto de un hospital. En junio de 1896 se nombró director médico de la construcción al doctor Liceaga y director general de la obra al ingeniero Gayol. ${ }^{30,31}$

La construcción se inició el 23 de julio de 1896 en un terreno de $170776 \mathrm{~m}^{2}$, ubicado en la Colonia Hidalgo, al poniente de la Calzada de la Piedad, cedido por el señor Pedro Serrano. En mayo de 1904, el ingeniero Gayol dejó la dirección técnica de la obra, quedando a cargo del arquitecto Manuel Robleda Guerra, quien la concluyó el 31 de diciembre de ese mismo año. Desde un principio, el proyecto consideraba la inclusión de dos pabellones: uno para niños con enfermedades no infecciosas y otro destinado a niños con enfermedades infecciosas. Estos pabellones se distinguirían de los demás por ventanales desde el piso y estarían rodeados por un corredor con barandal, cubierto de un techo ligero, donde los niños pudieran permanecer al aire libre la mayor parte del día. A poca distancia estaría la escuela, a donde acudirían los pacientes cuyas enfermedades lo permitiera. El departamento de niños con enfermedades infecciosas estaría aislado por medio de una barda, sería atendido por personal especial para cada grupo de enfermedades, la vajilla también sería distinta para cada grupo y cada cuarto tendría un vaciadero diferente para los líquidos de desecho y un postigo especial para pasar directamente las ropas al carrito que las conduciría a la estufa de desinfección. Asimismo, estaba indicado que tan pronto como se desocupara un cuarto destinado al aislamiento, se procedería a lavarlo y desinfectarlo y a la incineración de los objetos de poco valor que fueron infectados por el enfermo. ${ }^{32,33}$

A las 10 de la mañana del 5 de febrero de 1905, el presidente Porfirio Díaz, acompañado de su esposa doña Carmelita Romero, el vicepresidente, licenciado Ramón Corral, y todos los ministros de estado, inauguró el sueño más caro del doctor Liceaga: dotar a la Ciudad de México de un Hospital General digno y totalmente equipado.

El nosocomio inició sus actividades al día siguiente de la inauguración, cuando fueron trasladados 216 enfermos, seis provenientes del Hospital de Maternidad e Infancia. En lo que se refiere a la atención médica de los niños, se cumplió con lo programado por el doctor Liceaga, ya que contaba con 55 camas destinadas a la hospitalización de pacientes pediátricos, 31 en el Pabellón 23, donde se atendía a niños con patología no infecciosa, predominantemente quirúrgica, a cargo del doctor Eduardo Vargas; y 24 en el Pabellón 29, donde se brindaba atención a pacientes con patología infecciosa, a cargo del doctor Manuel G. Izaguirre. El cuidado de los recién nacidos quedó a cargo del doctor Manuel Perea en el Pabellón $24 .{ }^{31}$

La creación del Hospital General llevó a la clausura de los hospitales San Andrés, González Echeverría y el de Maternidad e Infancia, que se convirtió en el Consultorio Central, donde los enfermos podían solicitar una cama o ser atendido por padecimientos que no requerían hospitalización; en el caso de los niños, ahí se atendían pequeños traumatismos, enfermedades diatésicas en sus primeros periodos, padecimientos del aparato digestivo, entre otros. ${ }^{32}$

\section{El final}

El doctor Eduardo Liceaga y Torres, la figura más prominente de la medicina mexicana, director de la Escuela Nacional de Medicina, presidente del Consejo Superior de Salubridad, socio honorario y presidente en dos ocasiones de la Academia Nacional de 
Medicina, fundador del Conservatorio de Música, médico responsable de la sala de niños en el Hospital de San Andrés, primera en su tipo que hubo en el país, y primer director del Hospital de Infancia, falleció el 14 de enero de 1920.

\section{Bibliografía}

1. Kumate-Rodríguez J. Síntesis histórica: 1802-1994. En: Ávila-Cisneros I, Padrón-Puyou F, Frenk S, Rodríguez-Pinto M. Historia de la pediatría en México. México: Fondo de Cultura Económica; 1997.

2. Mendizábal G. Necrología. 1836-El Dr. Eduardo Liceaga†1920. ¡Aeternum vale! Gac Med Mex. 1920;1:63-68.

3. Liceaga E. Mis recuerdos de otros tiempos. México: Talleres Gráficos de la Nación. 1949.

4. Peza JD. La beneficencia en México. México: Imprenta de Francisco Díaz de León; 1881.

5. Flores FA. Historia de la medicina en México desde la época de los indios hasta la presente. México: Oficina Tipográfica de la Secretaría de Fomento; 1888

6. León N. La obstetricia en México. Notas bibliográficas, étnicas, históricas, documentarias y críticas de los orígenes históricos hasta el año de 1910. México: Tipográfica de la Vda. de F. Díaz de León, Sucesores; 1910.

7. Liceaga E. Exposición del descubrimiento del Dr. Koch y resultados obtenidos por los experimentadores que han empleado la linfa que usa ese profesor. Segunda parte. Inoculaciones de la linfa del Dr. Koch, en el hospital de niños. Gac Med Mex. 1891;26:121-133.

8. Vargas E. Sesión del 22 de enero de 1891. Acta número 16. Gac Med Mex. 1891;26:197-200.

9. Castañeda-De-Infante C. Catálogo de tesis de medicina del siglo XIX México: Universidad Nacional Autónoma de México; 1988.

10. Rodríguez-De-Romo AC, Castañeda-De-Infante C. Catálogo de las tesis de medicina del siglo XX. México: Facultad de Medicina/Universidad Nacional Autónoma de México; 1999.

11. Herrera-Jayme M. Algunas consideraciones sobre pediátrica. [Tesis] México: Facultad Médica de México; 1881

12. Liceaga $E$. Las inoculaciones preventivas de la rabia, estudio leído en la Academia de Medicina de México, en las sesiones de los días 18 de abril, 2 y 30 de mayo y 6 de junio de este año. México: Imprenta de Ignacio Escalante. 1888

13. Reyes A. Profilaxis de la rabia en México. Salubridad Pública. Documentos e informes presentados en la vigésima reunión anual de la Asociación Panamericana de la Salubridad Pública de 1892. EE. UU.: Republican Press Association; 1894
14. Liceaga E. Las inoculaciones preventivas de la rabia. Rev Med Mex. 1888:1:229-237.

15. Pruneda A. Centenario del nacimiento del Dr. Eduardo Liceaga. Gac Med Mex. 1940:68-91.

16. Liceaga E. Metritis crónica. Dispepsia. Neurosis sintomáticas. Curación. Gac Med Mex. 1869;4:193-196

17. Liceaga E. Importancia de divulgar la higiene personal. Gac Med Mex. 1915;10:344-347.

18. Domínguez M. Acta de la sesión del 9 de marzo de 1870. Gac Med Mex. 1870;5:84-88

19. Cabral J. Cirugía práctica. Una observación de traqueotomía, recogida por el alumno de la Escuela de Medicina D. Juan Cabral. Gac Med Mex. 1871;6:120-124

20. Liceaga E. Clínica externa. Resección sub-perióstica de la extremidad superior del fémur: curación; regeneración del hueso. Gac Med Mex. 1874:9:261-266.

21. Liceaga E. Cirugía práctica. Hospital de Infancia. Artritis supurada consecutiva a la viruela. Periostitis. Gac Med Mex. 1876:11:345-347.

22. Mejía D. Acta de la sesión del día 15 de mayo de 1878. Gac Med Mex. 1878;13:357-359.

23. Buisa JG. Cirugía. Periostitis difusa supurada; resección sub-perióstica. Regeneración. Curación. Gac Med Mex. 1878;13:361-368.

24. Liceaga E. Cirugía. Mal vertebral de Pott por osteítis central de los cuerpos de las vértebras dorsales. Absceso por congestión, de enormes dimensiones. Abertura amplia. Canalización. Curación. Gac Med Mex. 1878:13:351-357.

25. Liceaga E. Clínica quirúrgica. Hospital de Niños. Dos observaciones de cálculo vesical en los niños operados con buen éxito. Gac Med Mex. 1876;11:229-234.

26. Malanco F. Academia de Medicina. Sesión del 8 de junio de 1881. Acta No. 33 aprobada el 15 del mismo. Presidencia del Sr. Dr. Lucio. Gac Med Mex. 1881;16:298-299.

27. Liceaga E. Patología. Parálisis espinal seudo-hipertrófica. Gac Med Mex. 1884;19:470-475.

28. Liceaga E. Teratología. Despegamiento congénito del pabellón de la oreja derecha. Gac Med Mex. 1884;19:388-390.

29. Liceaga E. Terapéutica quirúrgica. Escoliosis dorsal derecha. Gac Med Mex. 1897;34:312-315

30. XLVI Legislatura de la Cámara de Diputados, los presidentes de México ante la nación. Informes, manifiestos y documentos de 1821 a 1866. Tomo II: Informes y respuestas desde el 1ํ de abril de 1876 hasta el 4 de noviembre de 1911. México: Imprenta de la Cámara de Diputados; 1966.

31. Anzures-López B. Remembranzas del inicio de la pediatría en el Hospital General de México. Rev Med Hosp Gen Mex. 1999:62:5-10.

32. Liceaga E, Gayol R. Proyecto de Hospital General de la Ciudad de México. Memorias del Segundo Congreso Médico Panamericano. México: Hoeck y Compañía Impresores y Editores; 1898.

33. Liceaga E. El Hospital General de la Ciudad de México. Cronica Med Mex. 1903;6:96-129. 